\title{
DESCONTMARKS: Scale Development and Validation
}

\author{
An Nur Nabila Ismail ${ }^{1}$, Yuhanis Abdul Aziz ${ }^{1}$, Norazlyn Kamal Basha ${ }^{1}, \&$ Anuar Shah Bali Mahomed ${ }^{1}$ \\ ${ }^{1}$ School of Business and Economics, Universiti Putra Malaysia, Serdang, Selangor, Malaysia \\ Correspondence: Yuhanis Abdul Aziz. E-mail: yuhanis@upm.edu.my
}

Received: January 5, 2021

Accepted: June 5, $2021 \quad$ Online Published: June 30, 2021

doi:10.5539/ass.v17n7p13

URL: https://doi.org/10.5539/ass.v17n7p13

\begin{abstract}
In order to attract more tourists to visit a particular place, destination content marketing plays an important role. Tourism research has recently shown an interest in destination content marketing; especially when tourism destination is advertised. Currently, there is no scale available to measure content marketing for promoting tourism destination. The present study has two primary objectives. First, to investigate the dimension of destination content marketing in destination related context. Second, to develop and validate a multiple-item scale for measuring content marketing towards tourism destination. This study uses a rigorous scale development technique which involves three stages of scale development using 3 separate studies. The study confirms that destination content marketing scale (DESCONTMARKS) comprises of three dimensions, measured with 10 items. The implications of the destination content marketing scale for practitioners, as well as suggestions for future research are provided.
\end{abstract}

Keywords: destination content marketing, scale development, validation, confirmatory factor analysis

\section{Introduction}

The world is filled with many exotic destinations that spark aggressive competition to lure in tourists and travellers. Therefore, effective advertising tactics are crucial in influencing tourists' decisions in choosing a particular destination. Destination authorities and practitioners depend on destination advertisements to attract potential travellers because a successful advertisement will promote tourist visitation. There are multiple mediums of advertising to promote tourist destinations such as televisions, radios, billboards, posters, information kiosks and many more (Spencer, 2013). However, it is challenging to identify the most effective advertising method. The high competition between destinations and the amount of general advertising in the market had encouraged the need to explore new marketing techniques to create novel advertising strategies that attract travellers.

Content marketing is a newly coined term by marketers and is considered a new marketing technique in the marketing industry. Content marketing practices a new method of strategic marketing, which involves the creation and sharing of mostly online material (such as videos, blogs, and social media posts). It has a different approach in comparison to traditional advertisements. Content marketing does not explicitly promote a brand but stimulates interest in the products or services. Even though it is getting popular among marketers and practitioners, limited studies had been done in the context of content marketing. Research in the field of content marketing is still at its initial stage. Traditional or old-fashioned advertisements such as slogans and pictures are typically used by destination marketers to promote places of attraction. On the other hand, content marketing provides meaningful, relevant and reliable information for travellers. Nonetheless, researchers have paid very little attention to exploring the details of content marketing. Moreover, the number of previous researches on content marketing measurement is close to none. Therefore, the lack of established dimensions and standardised instrumentation to measure tourists' perception of content marketing were apparent in the literature. The development of the content marketing scale is critically important because an established scale is important in any marketing research.

The unavailability of the scale to measure an important marketing tool such as content marketing may lead to difficulties in interpreting results in the areas of integrated marketing communication, especially advertisements and destination marketing. Moreover, the lack of information on the attributes and dimensions of content marketing may limit further research. Such information would increase the understanding of content marketing, thus provide constraints to scholars. Therefore, the current study attempted to explore the measurement of 
content marketing by reviewing advertising literature as a suitable foundation for content marketing. The purpose of the study was twofold.

First, to investigate the dimension of content marketing in the destination-related context. Second, to develop and validate a multiple-item scale to measure the destination content marketing (DESCONTMARKS) of tourism destinations. The emphasis on scale development appeared from the general concern that content marketing is a new marketing approach, which is imperative to market any destination as a field of study. Hence, additional research should be conducted to establish appropriate destination content marketing scales for further research. The findings of the present study are expected to examine the dimension of content marketing and its items and contribute to the limited works of literature on content marketing and destination marketing. A standard scale could provide researchers, destination managers and marketers with a tool to measure content marketing and therefore, provide for adequate analysis. This study also contributed to the field by delivering practical information that will enable destination managers to be better informed with the right attributes to promote destinations using accurate content marketing attributes. As such, this paper started with a review of the existing literature on content marketing, advertisements, and destination marketing.

\section{Literature Review}

\subsection{Destination Content Marketing}

Content marketing is a newly coined term in the area of marketing; however, it is not a new marketing discipline (Rahim \& Clements, 2012). According to the Content Marketing Institute (2016), content marketing is one of the marketing tactics that is focused on developing and distributing meaningful, relevant, and reliable content to attract and maintain consumers. It is crucial to provide valuable content that will make sure content marketing is successful (Steimle, 2014) and according to Vollero and Palazzo (2015), content marketing is part and parcel of marketing technique whereby marketers use the information and apply interesting ways to promote products or services. The objectives of content marketing are different from advertising because content marketing focused on creating brand awareness, customer involvement, and engagement (Vollero and Palazzo, 2015). As a result, Holliman and Rowley (2014) defined content marketing as the creation and spread of valuable content in various types of advertising to attract or maintain customers.

Previous works had limitedly examined content marketing in their research. For example, Kilgour, Sasser, and Larke (2015) examined the process of social media transformation, which included transforming content into a strategy. The findings revealed that there was a strong interest in applying the concept of content marketing in social media as advertising tools. The finding also indicated that there was a strong correlation between content and social media, which concluded that content marketing is suitable to be practiced in social media marketing. The findings from the interview with the marketers showed that marketers were willing to adopt content marketing as part of their advertising tools. Moreover, the study also reported that marketers were aware of the benefits of content marketing such as creating brand awareness and brand-building, as well as develop trust from customers.

According to Holliman and Rowley (2014), customers are seeking valuable information from the marketers or service providers in which valuable information is important in marketing. Hence, content marketing is one of the marketing techniques, which involves the sharing of information via videos, blogs, and social media posts to attract customers. Previous works of literature proved that limited research had been done on content marketing as the main construct. Apart from that, no scale had been developed to measure content marketing. However, the element of content marketing can be examined through the advertising perspective as a content marketer is concerned with the information that needs to be included in the advertisement. There is plenty of research that has been done in the area of advertising. However, none of them had paid attention specifically to content marketing such as Niazi, Siddiqui, Shah, and Hunjra (2012), who focused on the effectiveness of advertising in terms of emotional and environmental response towards consumer buying behavior. Besides, Rehman, Nawaz, Khan, and Hyder (2014) focused on how advertising affected the consumer buying behaviour, and the items for advertising focused only on the AIDA model, which included awareness, interest, desire, and action. However, the current study developed items for content marketing through elements that were in advertising and tested it on content marketing.

\subsection{Advertisement}

The present study reviewed the literature on advertisements to comprehend the content and notion of content marketing and the potential dimensions that may be associated with it. According to Bendixen (1993), advertising is one of the marketing techniques, which helps organisations to create awareness of new products or services, to inform the benefits and features of products or services to customers, to create a perception towards 
products or brands, and to persuade customers to purchase the products. Furthermore, Kotler and Keller (2008) defined advertising as any paid form of presentation or promotion on the products, services or ideas by an organisation.

Martin, Bhiny, and Agee (2002) stated that the advertisements should be interesting, demonstrative, utilises celebrities, do product comparisons, entertaining, contain payment information, and are fun. On the other hand, Mensah, Asuamah, and Amankwah (2013) claimed that elements such as animals or cartoon characters, celebrity endorsement, humour, fun, storyline, and music should be included in the advertisements. Additionally, Sachdeva (2015), advertisements should include the brand, celebrity endorsement, creating awareness, interesting, and host appearance. Based on a cross-reference literature examination in the area of advertising, researchers had identified 51 potential content marketing dimensions that served as a background to determine the content marketing dimensions. The present study emphasised on the identification of dimension and scale development therefore, the dimension was operationally defined in accordance with the study's purpose.

Based on the above discussions, it can be understood that content marketing may consist of several dimensions that may be different and unique depending on the nature of the destination itself. Therefore, based on the elements highlighted in previous research on advertising, the present study intended to determine the dimensions of content marketing and develop the scale to measure destination marketing. With these elements in mind, the discussions explained the relevance of content marketing in the context of promoting tourism destinations.

\subsection{Destination Marketing}

Destinations comprised of various attributes form parts of tourists' experiences. These attributes may also influence the choice of destination among travellers. According to Chi \& Qu, (2008) a favourable destination, which includes beautiful landscape, shopping opportunities, cultural exchanges, infrastructure, and tourism activities may have significant effects on an individual's destination choice. Therefore, it is very important for destination managers and marketers to use the right promotional strategies such as suitable content in the advertisement to promote the destination effectively.

The use of modern technology especially in terms of information sharing and communication is important in marketing to expose the uniqueness of a particular destination. According to Marasco et al. (2018), the number of destinations that uses technology in their marketing technique is increasing to attract and persuade potential travellers to visit their destination. Byun and Jang (2018) asserted that destination marketing can be done by marketers or service providers via destination advertising, which can help them attract tourists. Similarly, studies had proved that destination advertising can actually attract travellers to choose their destination (Seddighi \& Theocharous, 2002; Kim, Agrusa, \& Chon, 2014). Therefore, destination marketing and destination advertising significantly encourage travellers to choose a specific holiday destination. As mentioned earlier, content marketing is a new marketing technique among marketers in which they can advertise their destination by 'selling' information about their destination and attract the attention of potential travellers.

Langkawi is one of the prominent tourist destinations in Malaysia. It is gifted with 99 beautiful islands and offers a lot of attractions such as beaches, mangroves with rare flora and fauna, untaxed shopping, and attractive legendary stories (Tourism Malaysia, 2017). Not only that, according to Sinar Harian (2013), Langkawi has another main attraction spot, known as Machinchang, with sandstone of 550 million years of age. Langkawi is a growing tourist destination in Malaysia and the number of tourist arrival in Langkawi is constantly increasing annually (Fah \& Kandasamy, 2011) and according to Langkawi Development Authority (2017) the number of tourist arrival in Langkawi has been rising over the last decade. In 2016 alone, Langkawi received 3,634,517 tourists and it had increased up to 3,800,000 in 2017.

Today, plenty of destinations compete with Langkawi and are considered as substitutes for tourist visitations. Therefore, the government or service providers need to take progressive actions to promote Langkawi by developing an effective marketing strategy. It is crucial to implement a new marketing technique such as content marketing to help Langkawi lure in more tourists and become one of the competitive destinations in Malaysia. However, few studies had examined the relationships between the effectiveness of advertisement and promotions with destination choice, destination attributes, and others. Moreover, limited evidence suggested that content marketing had been examined in the context of a tourism destination as a choice among travellers. Although this area of study had recently appealed to the scholars, our understanding within this area remained poorly developed. 


\section{Methodology}

\subsection{Scale Development}

This study used a multi-staged scale development approach to foster a measurement scale for content marketing. Several guidelines from past studies were referenced to develop the scale (such as Churchill, 1979; Hinkins, 1995; Tsaur, Lin \& Liu, 2013; Choi, Law \& Heo (2016) and Yen, Tsaur \& Tsai, 2018). Four stages were taken to develop the DESCONTMARKS. Firstly, the generation of items that represented the attributes or items of content marketing. Next, scale purification, a procedure that involved the computation of Cronbach alphas and corrected item-total correlations, and the employment of exploratory factor analysis (EFA) to evaluate the scale dimensionality. During this procedure, item deletion was done to purify the tested scale. Then, the scale refinement was further tested via Confirmatory Factor Analysis (CFA). Finally, the CFA was further used to test the dimension and scale validation. Figure 1 illustrates the stages of scale development. All the respondents who participated in this study had visited Langkawi to ensure they were familiar with the landscape and characteristics of Langkawi.

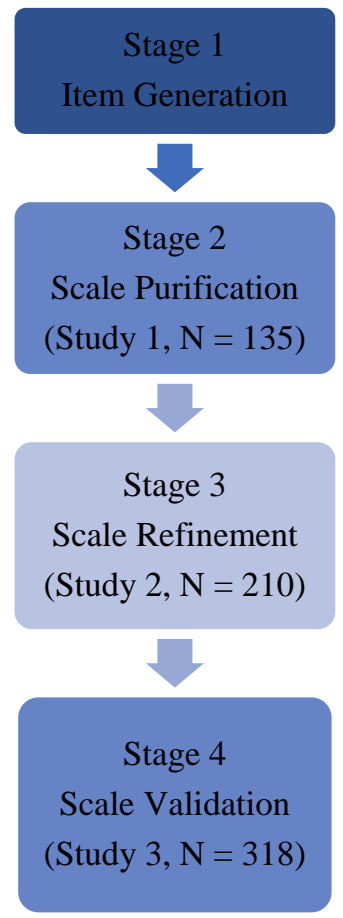

Figure 1. Stages of Scale Development

\subsection{Generation of Items}

Content marketing is a novel advertising strategy in which marketers develop and deliver meaningful, relevant, and reliable content to advertise a product or service and ultimately attract potential customers. However, content marketing is still new in the area of advertising with limited research at hand. Therefore, the current study explored content marketing based on advertising and analysed a few past studies on the elements of advertising to measure the elements in the context of content marketing. A set of 51 items that represented DESCONTMARKS was initially generated from a wide range of literature review. A five-point Likert scale was employed for this study as recommended by previous researchers (Marasco et al., 2018; Mansour \& Diab, 2016) as a result of its superior validity (convergent and discriminant).

\subsection{Scale Purification (Study 1)}

The data was collected from undergraduates in a Malaysian university.to purify the scale. Kim (2014) also conducted a scale development study with university students whereas for the present study students were also regarded as tourists. The respondents were first asked to recall their holiday experiences, specifically their visit to Langkawi, Kedah in Malaysia. Additionally, a short video on Langkawi was telecasted to recall the participants' memories and foster the process of data collection. Besides that, hardcopy brochures were also given out to the students while they were answering the survey questions. 
Langkawi was selected as the context of this study because of its diverse tourism portfolio. Langkawi is also one of the most visited destinations in Malaysia. Therefore, it is expected that most of the respondents had visited Langkawi at least once in their lifetime. Accordingly, purposive sampling was used to ensure that the data was obtained with sound judgement. Therefore, a deliberate choice of respondents was made based on their experiences of travelling. (which provided qualities to evaluate content marketing attributes). The respondents were asked to evaluate all 51 items on a 5-point Likert scale; in which, 1 represented strongly unimportant and 5 as strongly important. The questionnaire that was formulated consisted of three sections, which included content marketing, destination choice, and respondent profiles.

A total of $75.6 \%$ of the respondents were female whereas $24.4 \%$ of them were males. The majority of the respondents were Malays with a total of $77.8 \%$. Respondents were undergraduate students with a majority between the age of 18 and 24 years old. A total of 117 respondents had visited Langkawi and only 18 of them had never visited Langkawi before. Next, 43 of the respondents visited Langkawi once, 28 of them visited Langkawi twice and 30 of them visited Langkawi for at least 3 times. A total of 150 questionnaires were distributed, and 135 completed questionnaires were returned. Following the approach proposed by Churchill (1979), the initial scale was refined via the scale purification procedure so that a parsimonious scale can be achieved. Based on this approach, item-to-total correlations were computed, and those that were poorly correlated $(r<.4)$ with the total score were eliminated. This process resulted in the retention of 42 items from the original 51 items. Most of the studies chose factor loadings of more than 0.50 that were retained for further study (Kumar \& Nayak, 2015; Kim, 2014 and Churchill, 1979).

The Exploratory Factor Analysis (EFA) was later conducted by Varimax rotation to identify the psychometric properties of the new scale. The suitability of factor analysis was first determined by examining the Kaiser-Myer-Olkin (KMO) measure of sampling adequacy and Bartlett's test of sphericity. The EFA results showed that factor 1 explained the $27.14 \%$ variance whereas factor 2 was explained with $17.60 \%$ variance. A total of $6.20 \%$ variance was explained with factor 3, 5.69\% was explained with factor 4, and lastly, $4.40 \%$ variance was explained with factor 5. The KMO value was 0.441 and Bartlett's test of sphericity value was significant at the level 0.000 which justified the use of EFA.

The result of EFA proved that 42 items were loaded into the 5 factors of attributes of content marketing. The first factor consisted of items such as animated, attractive design, components, consumer motives, emotional tones, font selection, layout, navigation efficiency, packaging, price information, quality, safety, special effects, storyline, taste, trademark, and visually attractive. Items such as appeal, attractive message, availability, colours, company information, confidentiality, entertaining, interesting, music and page loading time were categorised under the second factor. The third factor comprised of the following items: attract the reader's attention, product identity, product overall presentation, slang, special offer, valuable content, and warranties. There were four items in the fourth factor such as internet address, national cultures, performance, and security. Lastly, four items such as brand, celebrity endorsement, host appearance, and humour were classified under the fifth factor.

\subsection{Scale Refinement (Study 2)}

The purpose of this study was to investigate the dimension of content marketing in destination related contexts and to develop and validate a multiple-item scale to measure content marketing in a tourism destination. For study 2, the retained items from study 1 , which comprised of 42 items were used, and some parts of the questionnaire were improved by adding travel behaviour as one of the sections to identify the travel behaviour of respondents. At this stage, the questionnaire was divided into four sections: travel behaviour, content marketing, destination choice, and respondents' profiles. The data collection for study 2 was distributed to the postgraduate students, which included local and international respondents to make sure that the results of the finding were more robust.

The second study was conducted on postgraduate students in public universities. About $30 \%$ of the respondents were male and $70 \%$ of them were females. Most of the respondents aged between 35 and 40 (47.1\%), followed by 31 and 34 years old, (32.9\%) and lastly, respondents who were 41 years old and above (20\%). The current study showed that $47.6 \%$ (100 respondents) were Malays, followed by $30 \%$ (63 respondents) of Chinese and $7.6 \%$ (16 respondents) of them were Indians. Next, the majority of the international respondents were students from Nigeria (12), followed by 8 students from Bangladesh and 4 from Iran. Additionally, 3 respondents were from Somalia, 2 respondents were from China whereas Libya and Yamen each had 1 representative in this study.

Seventy respondents were working with the government, which represented $33.3 \%$ of the total respondents. Around $30.5 \%$ of the respondents were private-sector employees, whereas $23.3 \%$ were businessmen. Another $12.9 \%$ were full-time students. Around $51.9 \%$ of the respondents earned RM7,001 to RM9,999, followed by 25.2\% 
who earned RM5,001 to RM7,000 and 21.4\% who earned RM3,001 to RM5,000 whereas another 1.4\% earned RM1,001 to RM3,000 monthly. The current study also found that most of the respondents had visited Langkawi 4 times.

Respondents were asked to remember and recall the beautiful and exclusive representation of Langkawi via a short video of the destination. After viewing the video, they needed to answer a set of questionnaires that contained 42 variables on content marketing and destination choice. This questionnaire took around 10 to 15 minutes to complete. Next, in the refinement stage of DESCONTMARKS, items with a low correlation value of below -.5 were eliminated (Yen, Tsaur and Tsai, 2018). Hence, 24 out of 42 items were eliminated. The remaining were 18 items that were used for the third study. The EFA results for the second study had shown that the KMO value was 0.395 and Bartlett's test of sphericity was significant at 0.000 .

The result of EFA provided evidence for the 18 items loaded onto the 4 factors of the attributes of content marketing. Seven items were sorted under the first factors: animated, attractive design, price information, quality, safety, special effects, and visually attractive. The second factor consisted of the following items: interesting, music, and page loading time. For the third factor, there were four items such as attract the reader's attention, slang, special offer, and warranties. Lastly, the fourth factor had four items such as internet address, national culture, performance, and security.

\subsection{Scale Validation (Study 3)}

Based on a study conducted by Choi, Law, and Heo (2016), the third data collection (study 3) was conducted among tourists in Langkawi to achieve the objective of the research. The data was collected using self-administered questionnaires in which most of the respondents took around 10 to 15 minutes to answer. This study used purposive sampling because it provided a sample that possessed qualities that were required by the study. This sampling technique is similar to study 1 and study 2 . The respondents were briefed about the objective of the study and all information about the respondents will be kept confidential. In total, 325 data were collected. Then the incomplete questionnaires were eliminated and the final number of the sample was 318 . The questionnaire was divided into four sections such as travel behaviour, content marketing, destination choice, and lastly respondent's profiles. Some improvements were done for travel behaviour and the respondent's profile in comparison to the previous studies. This was done to ensure that the questions were suitable for the current respondents. Table 1 explains the travel behaviour and respondent's profiles.

From the 318 respondents, $48.4 \%$ were male (154) and the remaining, 51.6\% were female (164). A total of 105 respondents were Malay, 88 were Chinese and 51 were Indian. Another 74 respondents were international tourists whereby it comes from many countries as shown in Table 2. Most of the respondents were private-sector employees $(18.9 \%)$, followed by students $(17.9 \%)$. Most of the respondents earned RM3,001 to RM5,000 per month. The current study also found that 86 respondents had visited Langkawi more than 5 times, whereas 42 respondents had visited Langkawi 4 times. The most popular choice of accommodation in Langkawi was 4-star hotels $(20.4 \%)$, followed by 3 -star hotels $(19.8 \%)$, and budget hotels with a total of $19.2 \%$. About $36 \%$ of the tourists stayed in Langkawi for 4 to 5 days. Most of them visited Langkawi for leisure (40.9\%), 32.4\% visited Langkawi for recreation and $23 \%$ of them visited Langkawi for shopping.

Table 1. Profile of Respondents and Travel Behaviours (Study 3, N = 318)

\begin{tabular}{lll}
\hline Variable & Study 3 & Percent \\
\hline Gender & & 48.4 \\
Male & 154 & 51.6 \\
Female & 164 & \\
\hline Age & & 19.5 \\
$18-24$ & 62 & 24.8 \\
$25-30$ & 79 & 20.8 \\
$31-34$ & 66 & 18.6 \\
$35-40$ & 59 & 16.4 \\
41 years and above & 52 & \\
\hline
\end{tabular}


Race

Malaysian: 244

Malay

105

33.0

Chinese

88

27.7

Indian

51

16.0

Non-Malaysian: 74

Poland

4

1.3

Denmark

3

0.9

UK

3

0.9

France

3

0.9

Netherlands

4

1.3

Russian

3

0.9

Australia

6

1.9

Canada

6

1.9

Egypt

9

2.5

China

11

3.1

Qatar

5

1.6

UAE

4

1.3

Brunei

5

1.6

Singapore

3

0.9

Indonesia

5

1.6

Occupation

Government

55

17.3

Private Employee

60

18.9

Businessman

51

16.0

Retired

34

10.7

Housewife

33

10.4

Student

57

17.9

Unemployed

28

8.8

Level of income

Below RM1000

13

4.1

RM1001-RM3000

45

14.2

RM3001-RM5000

91

28.6

RM5001-RM7000

62

19.5

RM7001-RM9999

59

18.6

Above RM100000

48

15.1

How many times have you visited Langkawi?

3

4

More than 5 times 


\begin{tabular}{lll}
\hline Type of accommodation & 65 & \\
Hotel-4 star & 63 & 20.4 \\
Hotel-3 star & 61 & 19.8 \\
Budget Hotel & 39 & 19.2 \\
Campsite & 28 & 12.3 \\
Homestay & 26 & 8.8 \\
Guest House & 36 & 8.2 \\
Apartment & & 11.3 \\
\hline Length of stay & 87 & \\
3 days & 116 & 27.4 \\
4 days & 115 & 36.5 \\
5 days & & 36.2 \\
\hline Purpose of visit & 12 & 3.8 \\
Business and Professional & 130 & 40.9 \\
Leisure & 103 & 32.4 \\
Recreations & 73 & 23.0 \\
Shopping & & \\
\hline
\end{tabular}

In study 3, data was collected in Langkawi and the respondents were approached at several popular places in Langkawi such as Pantai Chenang, Langkawi International Airport, Sky Bridge, Eagle Square, Langkawi Cable Car, and the Kuah Jetty. This final stage gave a clear result for the scale development process and helped to validate the dimensions and the items of DESCONTMARKS. Study 3 took about one week of the data collection process and the present study managed to obtain 325 responses from tourists. However, some data were eliminated because the answers were incomplete. Hence, the final number for study 3 was 318 . Out of 18 questions for content marketing, only 1 item received low factor loading, thus the final number of items for content marketing was 17 as shown in Table 2.

Table 2. Result of Factor Analysis for Study 3

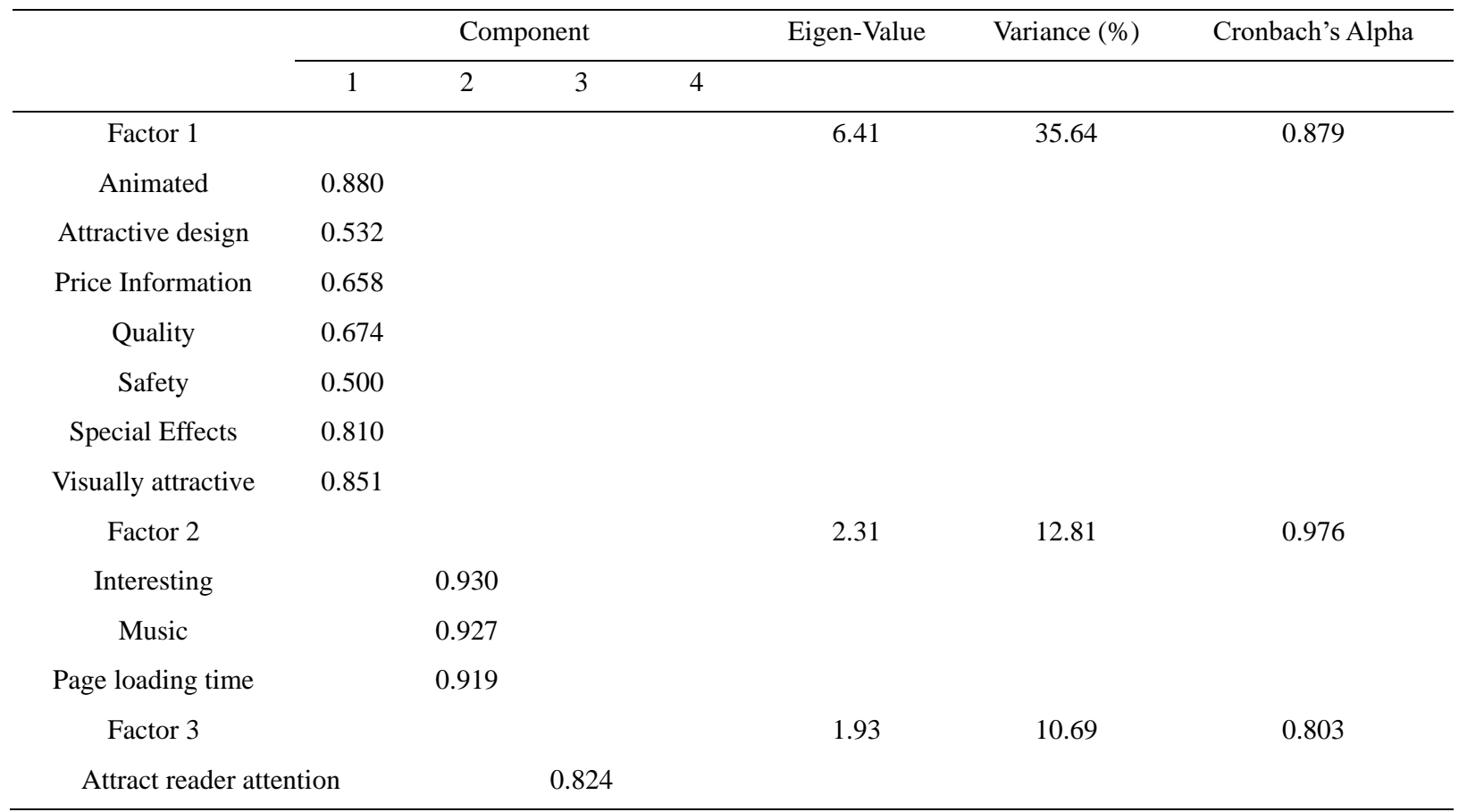




\begin{tabular}{|c|c|c|c|c|}
\hline Slang & 0.798 & & & \\
\hline Warranties & 0.661 & & & \\
\hline Factor 4 & & 1.19 & 6.58 & 0.777 \\
\hline Internet address & & & & \\
\hline National cultures & & & & \\
\hline Performance & & & & \\
\hline Security & & & & \\
\hline
\end{tabular}

The 17 items of DESCONTMARKS were divided into four different factors. In the first group, there were 7 items: animated, attractive design, price information, quality, safety, special effects, and visually attractive. For the second group, there were 3 items such as interesting, music, and page loading time. On the other hand, there were 3 items under the third group such as attract the reader's attention, slang and warranties. Lastly, for the fourth group, there were 4 items such as internet address, national cultures, performance, and security. The third stage of EFA results showed that the KMO value was 0.848 and Bartlett's test of sphericity value was significant at the level 0.000 .

\section{Confirmatory Factor Analysis (CFA)}

Confirmatory factor analysis (CFA) was conducted to confirm the validity of the 4-dimensional construct (four-factor model) and to identify the retained items in the previous exploratory factor analysis. The CFA used the maximum likelihood of AMOS. Table 4 shows that the factor loading for each item was between 0.630 and 0.990. The findings from the CFA showed that four items (attractive design, safety, quality, and special effects) had a low factor loading and the remaining items were 13. The average variance extracted (AVE) and composite reliability (CR) were computed to establish the reliability and validity of the dimensions. In particular, the values of AVE provided evidence to evaluate the convergent and discriminant validity of the scale. Table 3 summarises the computed value.

Table 3. Results of Initial Confirmatory Factor Analysis

\begin{tabular}{|c|c|c|c|c|c|c|}
\hline \multirow{2}{*}{ Factor } & \multicolumn{4}{|c|}{ Standardized Regression Weights } & \multirow[t]{2}{*}{ CR } & \multirow[t]{2}{*}{ AVE } \\
\hline & 1 & 2 & 3 & 4 & & \\
\hline Factor 1 & & & & & 0.919 & 0.793 \\
\hline Animated & 0.990 & & & & & \\
\hline Price Information & 0.730 & & & & & \\
\hline Visually attractive & 0.930 & & & & & \\
\hline Factor 2 & & & & & 0.970 & 0.915 \\
\hline Interesting & & 0.970 & & & & \\
\hline Music & & 0.940 & & & & \\
\hline Page loading time & & 0.960 & & & & \\
\hline Factor 3 & & & & & 0.818 & 0.603 \\
\hline Attract reader attention & & & 0.820 & & & \\
\hline Slang & & & 0.860 & & & \\
\hline Warranties & & & 0.630 & & & \\
\hline National cultural & & & 0.650 & & & \\
\hline \multicolumn{7}{|l|}{ Factor 4} \\
\hline Internet address & & & & 0.820 & 0.793 & 0.492 \\
\hline Performance & & & & 0.650 & & \\
\hline Security & & & & 0.670 & & \\
\hline
\end{tabular}


The current study decided to remove factor 4 as a result of an unsatisfied factor loading (internet address, performance, and security) because the items were not related to each other. For example, internet address and performance were more suitable for group 2 whereas security should be labelled under factor 1 . Hence, the items in group 4 were inconsistent and the current study had decided to remove factor- 4 completely. Table 4 represents the results for CFA. Based on Table 4, the factor loading for each item was between 0.630 and 0.990 .

Table 4. Results of Final Confirmatory Factor Analysis

\begin{tabular}{|c|c|c|c|c|c|c|}
\hline \multirow{2}{*}{ Factor } & \multicolumn{4}{|c|}{ Standardised Regression Weights } & \multirow{2}{*}{$\mathrm{CR}$} & \multirow{2}{*}{ AVE } \\
\hline & 1 & 2 & 3 & 4 & & \\
\hline Attractive & & & & & 0.919 & 0.793 \\
\hline Animated & 0.990 & & & & & \\
\hline Price Information & 0.730 & & & & & \\
\hline Visually attractive & 0.930 & & & & & \\
\hline Effective & & & & & 0.970 & 0.915 \\
\hline Interesting & & 0.970 & & & & \\
\hline Music & & 0.940 & & & & \\
\hline Page loading time & & 0.960 & & & & \\
\hline Convincing & & & & & 0.776 & 0.485 \\
\hline Attract reader attention & & & 0.820 & & & \\
\hline Slang & & & 0.860 & & & \\
\hline Warranties & & & 0.630 & & & \\
\hline National Cultures & & & 0.360 & & & \\
\hline
\end{tabular}

Table 4 also shows that the values of the 3 main dimensions were more than 0.50 and were up to par with the requirements of AVE. However, for group 3, the AVE was less than 0.50 with a total of 0.485 . According to Fornell and Larcker (1981), convergent validity is acceptable when the value of factor loading for all items is higher than 0.50 and the AVE score is larger than 0.50. Moreover, Fornell and Larcker (1981) claimed that if the AVE is less than 0.50 but the CR is more than 0.60 , the convergent validity is still acceptable. Therefore, the convergent validity of the dimensions was confirmed. In this case, all three dimensions were acceptable based on the value of factor loading, AVE, and CR, which suggested strong evidence of the scale reliability and validity. Besides, Table 5 shows that the reliability of items could be measured via the value of fit indices and its acceptable value.

Table 5. Criteria for Fit Indices from Several Authors

\begin{tabular}{ccc}
\hline Fit Indices & Authors & Recommended Value \\
\hline \multirow{2}{*}{ GFI } & Chau (1997) & $>0.90$ \\
& Segars and Grover (1993) & $>0.90$ \\
CFI & Bentler (1990) & $>0.90$ \\
& Hatcher (1994) & $>0.90$ \\
TLI & Bentler \& Bonett (1980) & $>0.90$ \\
RMSEA & Byrne (2001) & $<0.08$ \\
& Hu \& Bentler (1999) & $<0.05$
\end{tabular}

Table 6 depicts the overall fit indices. Initial results proved that the value of GFI was 0.964, CFI was 0.994, and TLI was 0.992, whereas the final result showed that the GFI was 0.975, CFI was 0.996, and TLI was 0.995. Therefore, both results met the requirement of more than 0.90 . However, the figure showed that the final result is 
better compared to the initial result. According to Byrne (2001), the value of RMSEA should be less than 0.08. In this case, the final value of RMSEA was 0.30 , which was better compared to the initial result $(0.37)$. However, the value was acceptable as it was below 0.08 .

Table 6. Initial and Final Result

\begin{tabular}{ccccc}
\hline Study 3 & GFI & CFI & TLI & RMSEA \\
\hline Initial Result & 0.964 & 0.994 & 0.992 & 0.37 \\
Final Result & 0.975 & 0.996 & 0.995 & 0.30 \\
\hline
\end{tabular}

All the values for each fit index in the final outcome met the requirements and were highly satisfactory. Hence, Figure 2 shows that the CFA results had appropriately represented the measurement model.

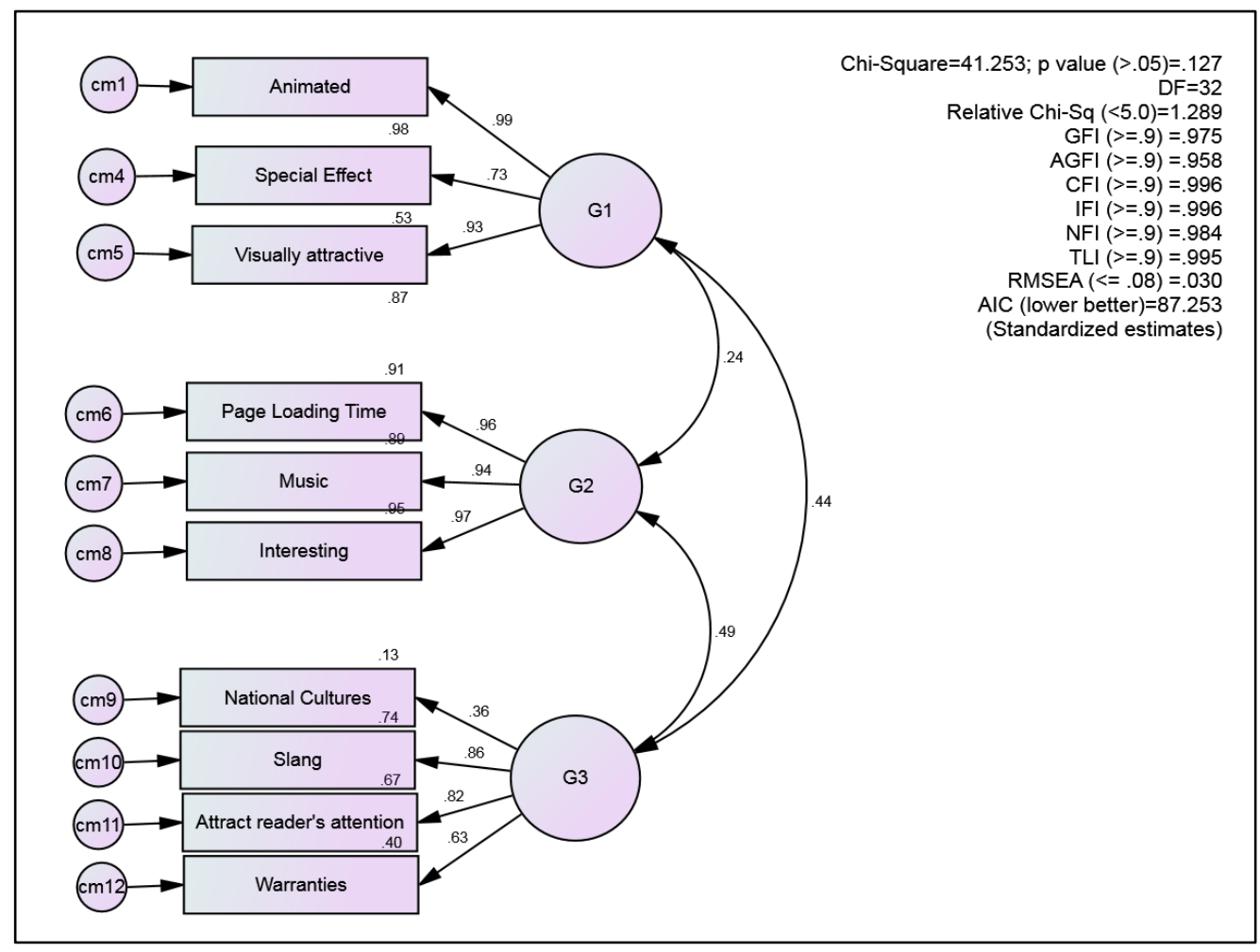

Figure 2. Measurement Model

\section{Discussion and Conclusion}

The study on content marketing is still at its initial stages. Therefore, the measurement of content marketing is almost unavailable. Although content marketing is a new marketing technique, which promotes products, services, and destinations, previous studies did not explicitly discuss the importance of content marketing is marketing and tourism literature. Moreover, content marketing is a developing area of research, and therefore, the literature remains sparse and the discussion is primarily limited to anecdotal discussion, which is quite unreliable because it was not scientifically established. This study is, therefore, significant because the findings add up to a growing body of literature on content marketing in the spectrum of new wave advertisements. Consequently, the outcomes of the present study provided scholars with innovative insights into the notion of content marketing, which is linked to destination marketing in tourism literature.

Therefore, the present study attempted to bridge the gaps by investigating the dimensions associated with content marketing to develop a scale of measurement for content marketing based on a review of the advertising sector. The current study referred to the scale development technique by Churchill (1979); Tsaur, Lin and Liu (2013); Choi, Law, and Heo (2016) and Yen, Tsaur and Tsai (2018). Four stages were involved based on 3 studies to develop a scale for content marketing. The first stage of the study involved the generation of items. Next, in the second stage (Study 1) data were collected from 135 undergraduate studies in public universities. Out of 51 
items, 9 items were deleted in the second stage. Hence, only 42 items of content marketing were used for the third stage of the scale development process.

The third stage involved postgraduate students (Study 2). It combined both local and respondents. During this stage, 24 items were deleted as a result of low factor loading. Hence, only 18 items remained in the fourth stage. The final stage of data collection was conducted in Langkawi, Malaysia, with a total of 318 local and international tourists. The EFA result showed 17 items had a factor loading higher than 0.50. Lastly, the study ran CFA to confirm the dimensions and items for content marketing. The current study found that there were 9 items loaded on a three-factor model that could be used to measure content marketing. The finding proved that the items used in this study were appropriate to measure content marketing since the result met all the requirements of fit indices, AVE and CR. Figure 1 shows that the three-dimensional construct was labelled as attractive, effective, and convincing.

The current study had introduced the concept of attractive for the first factor, which included items such as animated, special effects, and visually attractive. Attractive is an act of pleasing or an appealing feeling, which influences an individual. The present study measured the idea of attractiveness via digital advertising, which is content marketing. The element of animated, special effects, and visually attractive are becoming a major component, which may influence readers' attention. According to Mensah, Asuamah, and Amankwah (2013), special effects (76.6\%) bright colours that are visually attractive (50\%) and animation (24.6\%). are suitable and attractive advertising elements. The element of animated has become one of the important factors that make content marketing more attractive. The use of special effects as well as the attractiveness of visuals that marketers use in content marketing will attract travellers. Thus, the current study will classify the items of animated, special effects and visually attractive as an attractive factor.

According to Byun and Jang (2015), an effective destination advertisement will attract tourists to choose one particular destination. Hence, effectiveness in advertising promotes the effects of desire in decision-making, memory, attitude, and behaviour (Mansour \& Diab, 2016). As such, the current study had categorised the element of page loading time, music and interest under effective factors in which these three-elements influenced the consumers' attitude and their decision-making skills. The page loading time is important when it comes to digital marketing because a fast page loading time will keep viewers glued to a page and view the advertisements.

Hence, marketers should make sure the effectiveness of their marketing in terms of page loading time. Music is a common component of advertising. Music not only boosts customers' moods but also helps them recall products (Alpert, Alpert \& Maltz, 2005). Effective advertising will use music to attract more consumers and remind them of the products or brands. It is important to examine the element of persuasion when developing an advertisement. This is done to attract readers. The ability to convince encourages individuals to believe that the information of a product or service is true. Therefore, the current study had categorised national culture, warranties, slang, and attract the reader's attention under the convincing factor. National culture is an important element in advertising because this element attracts more readers, especially potential travellers, to choose the destination. Most the travellers love to visit other places to experience other cultures and gain some knowledge. Hence, marketers need to highlight the importance of culture in advertising. Liao (2018) stated that warranty is a guarantee and a promise that is offered by producers to buyers to insist that a product or service is safe and reliable. The present study included warranties as one of the elements in content marketing to influence the readers.

The marketers or service providers could develop advertisements on holiday destinations by guaranteeing that all the elements that they had highlighted in the advertisement were equivalent to the destination. Not only that, but the current study also included the element of slang as part of the convincing factor, which focused on advertisements in digital marketing. Slang in digital marketing can be defined as the numerous slang languages that are used by individuals in cyberspace (Liu, Wang \& Yu, 2017) as part of advertising methods. A study conducted by Liu, Wang, and Yu (2017) found that slang in the digital advertisement had influenced consumers' attitudes, as well as brands. Therefore, the slangs of mother-language can convince and attract potential customers. Moreover, slang is a cultural aspect, which motivates potential travellers to choose one particular destination. As a result, the current study had included slang as one of the convincing factors.

\subsection{Theoretical Implications}

No scale had been developed to measure DESCONTMARKS that focuses on the tourism area. The current study had contributed to the body of knowledge by developing and validating the items to measure the DESCONTMARKS. Additionally, the present study was the first to establish the scale for a new construct, 
chiefly the DESCONTMARKS which examines the decision-making process that may influence tourists in choosing one particular destination, in which the current study focused on Langkawi Island. Previous studies did not explore and develop DESCONTMARKS and its scale. Therefore, this study will be a foundation for the upcoming research that examines DESCONTMARKS.

This study made several methodological and conceptual contributions to the emerging areas of content marketing and destination marketing literature. First, a 9-item, three-dimensional scale of DESCONTMARKS was developed to measure content marketing in the context of the tourism destination. The results suggested that the DESCONTMARKS that emerged from the analysis was a multiple-item scale with adequate psychometric properties. Rigorous procedures with 3 different sets of data, developed a scale of measurement with 9-items into three dimensions. Accordingly, the present study proposed DESCONTMARKS as an instrument of content marketing for tourism, which can be utilised by both academicians and practitioners. Moreover, the study had expanded the existing knowledge of content marketing by consumers in general, and tourists in particular.

\subsection{Managerial Implications}

Based on the managerial and business implications, destination managers and marketers (tour operators) must pay special focus on the details of the attributes as established by DESCONTMARKS when they design the destination promotional packages. Online attributes such as animation, price information, quality, special effects, and visual appearances should be included to ensure the effectiveness of the advertisement content.

DESCONTMARKS generated the idea to marketers or government on important elements that should be focused on when they want to design destination advertisements. For example, the destination should have uniquely designed websites, social media, and online ad materials that stimulate potential tourists' imagination because selling intangible services like the destination is not an easy task. This will help marketers to develop an effective advertisement whereby the element that they use in advertising may attract potential travellers by exposing reliable content that a traveller needs. Not only that, the elements in content marketing not only can be used in the tourism industry, but can also be implemented in other industries such as food, cosmetics, health, and others. Besides, effective content marketing can create a popular and competitive destination in comparison to other places by highlighting more attractive activities, places and uniqueness in marketing to make sure that potential travellers know Langkawi better. Essentially, destination managers and marketers would benefit from this type of research since the DESCONTMARKS suggested three-dimensions with 10-items that were important content marketing attributes to facilitate the effective content advertisement to market the destination.

\subsection{Limitation and Directions for Future Research}

Although DESCONTMARKS was established based on a rigorous development procedure, there were several limitations in the present research. First, this study only focused on the quantitative approach and did not consider a qualitative perspective. Besides, the present study made reference to previous works of literature by Tsaur, Lin, and Liu (2013); Choi, Law, and Heo (2016) and Yen, Tsaur and Tsai (2018). These studies generated the items from focus groups whereas the present study generated items via extensive literature reviews. Therefore, future research should consider utilising both methods to provide more ideas on the production of items. Additionally, a qualitative study at an early stage of scale generation would benefit and could be subsidised to the refinement of the scale.

Next, the majority of the respondents in this study were Malaysians from Langkawi and therefore, it was difficult to generalise the findings of the study. Nevertheless, future research should focus on multi-ethnic samples from different groups of the population across the globe to examine the similarities and differences established in this study. This would develop a better understanding of the global attributes of destination content marketing. Third, the current study focused only on the measurement of content marketing based on tourism. Future research could, however, explore content marketing from multiple industries such as food and cosmetics to test specific attributes of content marketing. Finally, this study focused on one particular destination of choice. Langkawi is a unique island with specific characteristics that may not be found in other places. Nonetheless, different locations have distinctive characteristics and attractions that produce different features and results for DESCONTMARKS. Therefore, the attributes of specific destinations were integrated into the content of websites or advertisements to promote the destination better. Future research could conduct extend the comparative study to numerous travel spots and examine their attributes to enhance understanding. Moreover, future research should include other attributes of content marketing that were not covered in the present study.

\section{References}

Abernethy, A. M., \& Franke, G. R. (2013). The information content of advertising: A meta-analysis. Journal of 
Advertising, 1-17. https://doi.org/10.1080/00913367.1996.10673496

Al-Ababneh, M. (2013). Services quality and its impact on tourist satisfaction. Interdisciplinary Journal of Contemporary Research in Business, 4(12), 164-177.

Alpert, M. I., Alpert, J. I., \& Maltz, E. N. (2005). Purchase occasion influence on the role of music in advertising. Journal of Business Research, 369-376. https://doi.org/10.1016/S0148-2963(03)00101-2

Bendixen, M. T. (1993). Advertising effects and effectiveness. European Journal of Marketing, 19-32. https://doi.org/10.1108/03090569310045861

Bentler, P. M., \& Bonnet, D. C. (1980). Significance test and goodness of fit in the analysis of covarience structures. Psychological Bulletin, 588-606. https://doi.org/10.1037/0033-2909.88.3.588

Bentler, P. M. (1990). Comparative fit indexes in structural models. Psychological Bulletin.

Byrne, B. M. (2001). Structural equation modeling with AMOS, EQS, and LISREL: comparative approaches to testing for the factorial validity of a measuring instrument. International journal of Testing, 55-86. https://doi.org/10.1207/S15327574IJT0101_4

Byun, J., \& Jang, S. C. (2015). Effective destination advertising: Matching effect between advertising language and destination type. Tourism Management, 31-40. https://doi.org/10.1016/j.tourman.2015.01.005

Byun, J., \& Jang, S. C. (2018). “To compare or not to compare?”: Comparative appeals in destination advertising of ski resorts. Journal of Destination Marketing \& Management 10, 143-151. https://doi.org/10.1016/j.jdmm.2018.09.003

Chau, P. Y. (1997). Reexaming a model for evaluating information center succes using a structural equation modelling approach. Decision Sciences, 309-334. https://doi.org/10.1111/j.1540-5915.1997.tb01313.x

Chi, C. G. Q., \& Qu. H. (2008). Examining the structural relationships of destination image tourist satisfaction and destination loyalty: An integrated approach. Tourism Management, 29, 624-636. https://doi.org/10.1016/j.tourman.2007.06.007

Choi, H. S. (2005). Measuring Residents' Attitude toward Sustainable Tourism: Development of Sustainable Tourism Attitude Scale. Journal of Travel Research, 380-394. https://doi.org/10.1177\%2F0047287505274651

Choi, M., Law, R., \& Heo, C. Y. (2016). Shopping destination and trust - Tourist attitude: Scale development and validation. Tourism Management, 490-501. https://doi.org/10.1016/j.tourman.2016.01.005

Churchill, G. A. (1979). A paradigm for developing better measures of marketing constructs. Journal of Marketing Research, 63-73. https://doi.org/10.2307/3150876

Content Marketing Institute. (2016). Retrieved from https://contentmarketinginstitute.com

Fah, L. K., \& Kandasamy, S. (2011). An investigation of services quality and customer satisfaction among hotels in Langkawi. International Conference on Management, 731-748.

Fornell, C., \& Larcker, D. F. (1981). Evaluating structural equation models with unobservable variables and measurement error. Journal of Marketing Research, 39-50. https://doi.org/10.1177\%2F002224378101800104

Hatcher, L. A. (1994). Step-By-Step Approach to Using the SAS System for Factor Analysis and Structural Equation modelling (2nd ed.). SAS Institute Inc: North Carolina, USA

Hinkin, T. R. (1995). A review of scale development practices in the study of organizations. Journal of Management, 21(5), 967-988. https://doi.org/10.1016/0149-2063(95)90050-0

Holliman, G., \& Rowley, J. (2014). Business to business digital content marketing: Marketers' perceptions of best practice. Journal of Research in Interactive Marketing. 269-293. https://doi.org/10.1108/JRIM-02-2014-0013

Hu, L. T. (1998). Fit Indices in Covariance Structure Modeling: Sensitivity to Underparameterized Model Misspecification. Psychological Methods, 424-453. https://doi.apa.org/doi/10.1037/1082-989X.3.4.424

Kilgour, M., Sasser, S. L., \& Larke, R. (2015). The social media transformation process: Curating content into strategy. Corporate Communications: An International Journal, 20(3), 326-343. https://doi.org/10.1108/CCIJ-07-2014-0046

Kim, S. S., Agrusa, J., \& Chon, K. (2014). The influence of a TV drama on visitors' perception: A cross-cultural 
study. Journal of Travel \& Tourism Marketing, 31(4), 536-562. https://doi.org/10.1080/10548408.2014.883950

Kotler, P., \& Keller L. K. (2008). Marketing Management (13th ed.). Upper saddle River: Pearson Prentice Hall.

Kumar, V., \& Nayak, J. K. (2015). Destination personality: Scale development and validation. Journal of Hospitality and Tourism Research, 1-23. https://doi.org/10.1177\%2F1096348014561027

Kus, O. (2016). The influence of cultural background on content marketing practices: the approach of Turkish and Lithuanian youth to the main components of content marketing. Informacijous Mokslai, 45-60. https://doi.org/10.15388/Im.2016.76.10381

Langkawi Development Authority. (2017). Retrieved May 18, 2017, from Tourism Langkawi: www.lada.gov.my

Liao, B. (2018). Warranty as a competitive dimension for remanufactured products under stochastic demand. Journal of Cleaner Production, 511-519. https://doi.org/10.1016/j.jclepro.2018.07.013

Liu, S., Wang, Y., \& Yu. S. (2017). The effect of different internet slang style on brand personality and ad persuasion. Transdisciplinary Engineering: A Paradigm Shift. https://doi.org/10.3233/978-1-61499-779-5-197

Mansour, I. H. F., \& Diab, D. M. E. (2016). The relationship between celebrities' credibility and advertising effectiveness: The mediation role of religiosity. Journal of Islamic Marketing, 7(2), 148-166. https://doi.org/10.1108/JIMA-05-2013-0036

Marasco, A., Buonincontri, P., Niekerk, M. V., Orlowski, M., \& Okumus, F. (2018). Exploring the role of next-generation virtual technologies in destination marketing. Journal of Destination Marketing \& Management, 9, 138-148. https://doi.org/10.1016/j.jdmm.2017.12.002

Martin, B. A. S., Bhimy, A. C., \& Agee, T. (2002). Infomercials and advertising effectiveness: An empirical study. Journal of Consumer Marketing, 468-480. https://doi.org/10.1108/07363760210444850

Mensah, P. A., Asuamah, S. Y., \& Amankwah, J. (2013). Consumer's attitude towards advertisment elements: A survey of marketiing students in Sunyani Polytechnic, Ghane, West Africa. International Journal of Innovative Research in Management, 13-24.

Niazi, G. S. K., Siddiqui, J., Shah, B. A., \& Hunjra, A. I. (2012). Effective advertising and its influence on consumer buying behavior. Information Management and Business Review, 4(3), 114-119.

Patsioura, F., Vlachopoulou, M., \& Manthou, V. (2009). A new advertising effectiveness model for corporate advertising web sites: A relationship marketing approach. Benchmarking: An International Journal, 372-386. https://doi.org/10.1108/14635770910961380

Rahim, K., \& Clemens, B. (2012). Organizational Goals and Performance Measurement Criteria for Content Marketing. Journal of Communiction and Computer, 876-904.

Rajaei, Y., Ahmadi, M., Rahmani, M., \& Samadi, M. (2014). Impact of key elements of advertising billboard on consumer and prioritize the element using the AHP technique. International Journal of Innovative Research in Advanced Engineering, 334-342.

Rehman, F. U., Nawaz, T., Khan, A., \& Hyder, S. (2014). How advertising affects the buying behavior of consumers in rural areas: A case of Pakistan. Academic Research International, 5(4), 405- 412.

Sachdeva, R. (2015). Assessment of advertising effectiveness: A scale validation exercise. Samvad International Journal of Management, 15-25.

Seddighi, H. R., \& Theocharous, A. L. (2002). A model of tourism destination choice: A theoretical and empirical analysis. Tourism Management, 23(5), 475-487. https://doi.org/10.1016/S0261-5177(02)00012-2

Segar, H. (1993). Re-examining perceived ease of use measurements and perceived usefulness. Decision Sciences, 17(4), 517-525. https://doi.org/10.2307/249590

Spencer, D. M. (2013). Effectiveness of intra-destination television advertising of tourist attractions and facilities. Journal of Destination Marketing and Management, 155-164. https://doi.org/10.1016/j.jdmm.2013.05.003

Steimle, J. (2014, September 19). What is Content Marketing. Retrieved from Forbes Online: http://www.forbes.com/sites/joshsteimle/2014/09/19/what-is-content-

Tourism Malaysia. (2017). Malaysia Tourism Statistics. Tourism Malaysia.

Tsaur, S. H., Lin, W. R., \& Liu, J. S. (2013). Sources of challenge for adventure tourists: Scale development and 
validation. Tourism Management, 85-93. https://doi.org/10.1016/j.tourman.2013.03.004

Turley, L. W., \& Kelley, S. W. (2013). A comparison of advertising content: Business to business versus consumer services. Journal of Advertising, 39-48. https://doi.org/10.1080/00913367.1997.10673534

Usman, M. (2013). Creation of effective advertising in the persuasion of target audience. International Journal of Economics, Finance and Management, 77-82.

Vollero, A., \& Palazzo, M. (2015). Conceptualizing content marketing: a Delphi approach. Journal of Italian Marketing Society, 25-44. https://doi.org/10.3280/MC2015-001003

Wang, K. C., Jao, P. C., Jin, Y. S., \& Guo, Y. Z. (2009). Exploring attractive message in group package tour newspaper advertisements. International Journal of Advertising, 843-862. https://doi.org/10.2501/S0265048709200928

World Economic Forum. (2017). The Travel \& Tourism Competitiveness Report 2017.

World Tourism Organization (UNWTO). (2017). UNWTO Tourism Highlights 2016 edition.

World Travel \& Tourism Council. (2017). Travel \& Tourism Economic Impact 2017 World.

Yen, C. H., Tsaur, S. H., \& Tsai, C. H. (2018). Tour leaders' job crafting: Scale development. Tourism Management, 52-61. https://doi.org/10.1016/j.tourman.2018.05.017

\section{Copyrights}

Copyright for this article is retained by the author(s), with first publication rights granted to the journal.

This is an open-access article distributed under the terms and conditions of the Creative Commons Attribution license (http://creativecommons.org/licenses/by/4.0/). 